\title{
Motivations for Consonant Epenthesis in Nonstandard Suffixed Forms of Korean Nouns
}

\author{
Ji Yea Kim \\ Stony Brook University
}

\section{Introduction}

Consonant clusters are universally more marked than simplex consonants, and different languages exhibit different strategies to eliminate or minimize the marked structure. For example, consonant deletion occurs in Québec French (e.g., /putr/ [pot] 'beam') while vowel epenthesis does in Cairene Arabic (e.g., /katab-t-l-ha/ [ka.tab.til.ha] 'I wrote to her' (Côté 2000). Korean is a language like the former where stemfinal consonant clusters are obligatorily simplified via consonant deletion in isolation forms of nouns. In addition, consonant deletion can optionally occur in nonstandard Korean when nouns are followed by a vowel-initial suffix (e.g., $-i$ NOM). Previous research has agreed on the optionality of consonant cluster simplification and presented different analyses on this (Y. Lee 2001, Kenstowicz 1996, Ko 2006, Yun 2008). ${ }^{1}$ In addition to these well-known variants of suffixed forms of nouns with and without consonant deletion, there is another form that has not yet been studied. It is suffixed forms of nouns with consonant epenthesisparticularly with [s]-epenthesis.

The [s]-epenthesis phenomenon in nonstandard Korean has been underestimated and reported as an onetime speech error (Jun \& J. Lee 2007). However, I show in this paper that suffixed forms of nouns with consonant epenthesis occur systematically although it is not as frequent as others with consonant deletion. I provide an analysis of what motivates consonant epenthesis and why it is [s] but not any other consonant that is epenthesized.

The organization of this paper is as follows. In Section 2, I provide a background of variation in the treatment of stem-final consonant clusters in Korean nouns. In order to show that the less-studied forms with consonant epenthesis occur systematically, I summarize a production experiment and its results in Section 3. In Section 4, I provide analyses of the suffixed forms of nouns with consonant epenthesis in terms of segmental and suprasegmental aspects, and the quality of the epenthetic consonant [s].

\section{Background}

In Korean, there are six consonant clusters that appear in nouns: /ps/, /ks/, /ls/, /lp/, /lk/, and /lm/. ${ }^{2}$ All of

\footnotetext{
* I would like to thank Lori Repetti for her invaluable comments and guidance, and Jiwon Yun and Jeffrey Heinz for their helpful suggestions. Also thanks to the Stony Brook Phonology Reading Group, audience and anonymous reviewers at the 26th Manchester Phonology Meeting and the 6th Annual Meeting on Phonology. I would like to express my gratitude to the Center for Korean Studies at Stony Brook University and the Embassy of the Republic of Korea in the USA for their scholarships. All errors are my own.

1 The obligatory consonant cluster simplification in Korean occurs only for nouns but not for other lexical categories, such as verbs or adjectives. This is due to the noun-verb asymmetry in Korean. Nouns can appear either in isolation forms or in suffixed forms. When nouns are in isolation, consonant clusters undergo obligatory simplification (e.g., /talk/ [tak] 'chicken'). On the other hand, verbs cannot stand alone (e.g., *ilk 'to read') but are mandatorily followed by a suffix (e.g., ilk-ta 'read-DEC'). This indicates that verbs do not have isolation forms, and thus they do not exhibit variation in stem-final consonant clusters. For this reason, the present study limits its scope of investigation to nouns in Korean. For detailed discussions on the noun-verb asymmetries in Korean, see Y. Lee (2001) and Yun (2008) among others.

2 There are in fact 11 input consonant clusters in Korean: /ps/, /ls/, /ks/, /nc/, /lth/, /lh/, /nh/, /lk,$/ l \mathrm{p} /, / 1 \mathrm{p}^{\mathrm{h}} /$, and $/ \mathrm{lm} /(\mathrm{Ko}$ 2006 based on Y. Lee 1993). Among these, only the six that are underlined occur in nouns, which are of interest in this study.
}

(C) 2019 Ji Yea Kim

Proceedings of AMP 2018 
them occur in post-vocalic position. Variation in their realization depends on whether noun stems are in isolation or suffixed.

$$
\begin{aligned}
& \text { Isolation: /talk/ [tak] } \\
& \text { Suffixed: /talk-i/ a. [tal.ki] } \\
& \sim \text { b. [ta.ki] } \\
& \sim \text { c. [tak.si] } \\
& \text { 'chicken' } \\
& \text { 'chicken-NOM' } \\
& \text { 'chicken-NOM' } \\
& \text { 'chicken-NOM' }
\end{aligned}
$$

(No variation across varieties)

(Standard: $\quad$ CC preserved)

(Nonstandard I: one $\mathrm{C}$ preserved)

(Nonstandard II: one C preserved $+[\mathrm{s}]$ )

Consonant clusters are obligatorily reduced to a simplex coda consonant if noun stems are in isolation (e.g., /talk/ [tak], *[talk] 'chicken'), as in (1). This is motivated by the Coda Law in Vennemann's (1988) preference laws for syllable structure, which states that it is more preferred if a syllable coda consists of a smaller number of sounds.

In contrast, suffixed forms show variation when a vowel-initial suffix (e.g., $-i$ NOM) is attached, as in (2a-c). It is standard to preserve both elements of the consonant cluster when noun stems are followed by a vowel-initial suffix. As shown in (2a), the first element is syllabified as coda and the second as onset (i.e., /talk-i/ [tal.ki] 'chicken-NOM'). In nonstandard Korean, however, consonant deletion often occurs even for suffixed forms of nouns (e.g., /talk-i/ [ta.ki] 'chicken-NOM'), as in (2b). The consonant that is preserved in (2b) is the very consonant that remains in isolation form [tak] in (1), at the expense of the other consonant $/ 1 /$.

The last and the most innovative form is the one that occurs via consonant epenthesis as well as consonant deletion in another nonstandard variety of Korean (e.g., /talk-i/ [tak.si] 'chicken-NOM'), as in (2c). This form is distinctive from the other variants, in that it has the consonant [s], which is non-etymological and thus epenthetic. [s]-epenthesis is reported as a one-time speech error made by a native speaker of Kyungsang Korean in Jun \& J. Lee's (2007) experiment (e.g., /pap-i/ [pap.si] 'rice-NOM'). In their findings, [s] appeared after the noun pap 'rice', which has the simplex consonant $/ \mathrm{p} /$ in the stem-final position. If the speaker had not epenthesized [s], the output form would have been [pa.pi], which is structurally less marked (i.e., codaless) and conforms to the standard Korean phonology. A reasonable question we can then pose is what motivates consonant epenthesis, which is a seemingly needless action to take. As an extension of the observation of [s]-epenthesis in suffixed forms of nouns with a simplex consonant, the present study shows that $[\mathrm{s}]$-epenthesis also occurs in suffixed forms of nouns with a consonant cluster, as in (2c).

\section{Experiment}

3.1 Participants Twenty native speakers of Seoul Korean (a dialect spoken in the Seoul metropolitan area) were recruited to participate in a production experiment (mean age: 23; range: 19-27). They were all undergraduate or graduate students at Stony Brook University.

3.2 Materials Prior to conducting the production experiment, speech materials were selected from two versions of the Sejong Corpus of Korean (The National Institute of the Korean language): written (3rd edition; 2010) and spoken (4th edition; 2011). The purpose of using these corpora was to select nouns that are actually in use in contemporary spoken Korean since nouns with a consonant cluster are particularly limited in number compared to those with a simplex consonant. I selected 15 nouns that occur with one of the six stem-final consonant clusters /ps/, /ks/, /ls/, /lp/, /lk/, and /lm/ (e.g., jıtılp 'eight', talk 'chicken'). Also selected for comparison were 14 nouns with one of the 12 input stem-final simplex consonants $/ \mathrm{p} /, / \mathrm{p}^{\mathrm{h}} /, / \mathrm{t}^{\mathrm{h}} /$, /s/, /k/, /k' /, /c/, /ch/, /n/, /m/, /y/, and /l/ (e.g., kıp 'fear', cuk 'porridge', pu^k 'kitchen'). In this way, 29 nouns were selected and used in the present study.

3.3 Procedure Participants were presented the 29 nouns in the production experiment. The nouns were presented auditorily and visually with pictures in order to minimize the spelling effect since in orthography consonant clusters appear with no deletion of any element.

Participants were asked to say the nouns with suffixed forms by using the conjunctive suffix -iray 'and': for example, san sokii hilk-iran tol 'soil in the mountain and stone'. This particular conjunctive suffix was used in this study in order to show that variation with [s]-epenthesis occurs beyond the noun paradigms where vowel-initial case markers (e.g., $-i$ NOM, $-\dot{i} l$ ACC, $-e$ DAT/LOC) are attached to nouns, as were in previous 
research (e.g., Ko 2006, Jun 2010). In addition, the suffix -iray 'and' is spoken in a casual and colloquial setting more often than its more formal counterpart $(k) w a$ 'and'. By using the suffix -iray 'and', therefore, it was expected to elicit nonstandard forms more effectively. Overall, 2,560 suffixed forms of nouns were elicited and recorded during the experiment. The number of recorded items with [s]-epenthesis was counted for analysis, excluding the ones produced with an error or a pause between the noun stem and the suffix, or the ones recorded in training sessions.

3.4 Results Variants with [s]-epenthesis occurred in nouns with the stem-final consonant clusters /lp/

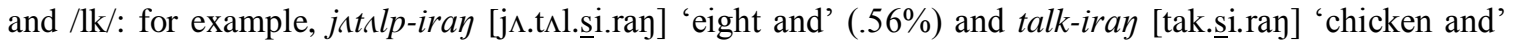
$(5.90 \%)$. [s]-epenthesis also occurred in nouns with a stem-final simplex consonant, which is not coronal or sonorant: for instance, $/ \mathrm{p} /, / \mathrm{k} /$, and $/ \mathrm{k}^{\mathrm{h}} /$ in $k \wedge p$-iray [kıp.si.ray] 'fear and' (8.33\%), cuk-iray [cuk.si.ray] 'porridge and' (1.67\%), and punk $k^{h}$-iray [pu.sk.si.ray] 'kitchen and' (6.67\%). Suffixed forms of nouns with [s]-epenthesis are by no means frequent in occurrence. However, it is notable that it is only [s] but not any other consonant that is epenthesized in the suffixed forms of nouns. This implies that [s]-epenthesis is not due to an unsystematic speech error, but that there is more to it than that.

\section{Discussion and conclusion}

4.1 Identity to the Base at the segmental level Before we begin the discussion of the epenthetic consonant, it is necessary to identify whether stem-final consonant clusters are preserved or simplified in nonstandard suffixed forms of nouns. In /talk-iran/ [tak.si.ray] 'chicken and', for example, the coda consonant of the first syllable (i.e., [k]) appears to be part of the consonant cluster /lk/ in the noun stem talk 'chicken'. Among the two elements of the consonant cluster, however, $/ \mathrm{k} /$ is preserved both in the isolation form (i.e., /talk/ [tak] 'chicken') and in the nonstandard suffixed form /talk-iray/ [ta.ki.ray] 'chicken and'. This is referred to as segmental identity in the present study.

Segmental identity among isolation forms and two varieties of nonstandard suffixed forms of nouns, noun stem talk 'chicken'
a. Isolation:
[tak] 'chicken'
b. Nonstandard suffixed forms of nouns with consonant deletion: [ta.ki.ray] 'chicken and'
c. Nonstandard suffixed forms of nouns with consonant epenthesis: [tak.si.ray] 'chicken and'

The identity between suffixed forms and isolation forms can be accounted for by the output-output (OO) correspondence constraint BASE-IDENTITY (Kenstowicz 1996). This constraint requires that isolation forms must be the Base to which nonstandard suffixed forms make reference. Agreeing with the general idea of the Base identity effect, I argue that the constraint BASE-IDENTITY should be specified as BASE-IDENTITY-SEG, which states that nonstandard suffixed forms should be identical to the Base at the segmental level.

BASE-IDENTITY-SEG (taken from Kenstowicz 1996 and modified): Given an isolation form [X], output candidates of suffixed forms are evaluated for how well they match $[\mathrm{X}]$ at the segmental level. (i.e., segmental identity)

BASE-IDENTITY-SEG requires the suffixed forms of Korean nouns conform to the structure "isolation form + V-initial suffix", as in (3b). Preserving the segmental identity of the isolation form is also crucial for the analysis of the nonstandard suffixed forms of nouns with [s]-epenthesis, as in (3c), since the same mechanism for segmental preservation plays a role in both varieties of nonstandard Korean. This can also be accounted for by the principle of lexical conservatism (Steriade 2000). This refers to the dependence of novel forms on listed forms within a language. To apply this notion to the preserved consonant in suffixed forms of Korean, the isolation form [tak] 'chicken' functions as the precedent since it already exists in the language and thus is listed. For this reason, [ta.ki] is selected as the optimal nonstandard suffixed form /talk-i/ 'chicken-NOM'. The other option *[ta.li] is ruled out because *[tal] is not the attested isolation form of talk 'chicken' in Korean. 
4.2 Identity to the Base at the suprasegmental level In nonstandard suffixed forms of Korean nouns with consonant epenthesis, the epenthetic consonant [s] consistently occurs in onset position of the second syllable (e.g., /talk-iray/ [tak.si.ray] 'chicken and'). What precedes [s] is the coda consonant [k] of the first syllable, which originates from the isolation form [tak] 'chicken'. We have seen that this is due to the requirement of being identical to the Base at the segmental level, which was represented as the above proposed constraint BASE-IDENTITY-SEG. This is, however, not enough to fully account for the variation. In other words, BASE-IDENTITY-SEG fails to explain why certain consonants should be in a certain position. What is not taken into consideration is the fact that nonstandard suffixed forms with consonant epenthesis are identical to isolation forms in terms of the position of the preserved consonant. I refer to this as suprasegmental identity in this paper.

Suprasegmental identity between isolation forms and nonstandard suffixed forms of nouns with consonant epenthesis, noun stem talk 'chicken'
a. Isolation:
[tak] 'chicken'
b. Nonstandard suffixed forms of nouns with consonant epenthesis:[tak.si.ran] 'chicken and'

Comparing the isolation form [tak] 'chicken' (5a) and nonstandard suffixed forms of nouns with consonant epenthesis [tak.si.ran] 'chicken and' (5b), it is obvious that the identity to the Base is required at the suprasegmental level - to be more specific, at the syllable level. Another OO-correspondence constraint is thus needed to account for this: BASE-IDENTITY-SYL, which I borrow from CORR- $\sigma$-ROLE (Aguero-Bautista 1998 in Kenstowicz 2005). As its name suggests, this constraint applies at the suprasegmental level.

BASE-IDENTITY-SYL (taken from Aguero-Bautista 1998 in Kenstowicz 2005 and modified)

"...[I]f $\mathrm{x}$ and $\mathrm{y}$ are corresponding segments then $\mathrm{x}$ and $\mathrm{y}$ have the same syllabic analysis (onset, nucleus, coda).” (i.e., suprasegmental identity)

The job of BASE-IDENTITY-SYL is to require the syllabic profile (onset, nucleus, coda) of suffixed forms be identical to that of isolation forms. In other words, an epenthetic consonant is required in order to have the coda consonant [k] from [tak] 'chicken' also be in coda position in the nonstandard suffixed form [tak.si.ray] 'chicken and'.

4.3 Quality of the epenthetic consonant In order to maintain the coda position of the first syllable with the same consonant preserved from the isolation form, it is necessary to epenthesize a consonant in onset position of the second syllable otherwise the preserved consonant would be syllabified as onset of the second syllable, as in /talk-iran/ [ta.ki.ray] 'chicken and'. In sum, consonant epenthesis is motivated by the suprasegmental identity to the Base. It is intriguing that the epenthetic consonant is always [s] but not any other consonant. While [s]-epenthesis has been paid little attention or regarded as a speech error, I show in this study that it is observed consistently and that there should be reliable reasons for native Korean speakers' choice.

I propose [s]-epenthesis is due to the analogy from the dominant pattern found in suffixed forms of nouns in Korean. In particular, stem-final coronal obstruents $/ \mathrm{s} /, / \mathrm{t}^{\mathrm{h}} /, / \mathrm{c} /$, and $/ \mathrm{c}^{\mathrm{h}} /$ are usually neutralized to [s] when a vowel-initial suffix is attached (Jun 2010 adopting the paradigm learning model in Albright 2002a, b, 2005, 2008).

\author{
Variation in stem-final coronal obstruents in Korean (Jun 2010) \\ /soth-e/ 'pot-DAT' \\ a. [so.the] (standard) \\ b. [so.te] (nonstandard) \\ c. [so.che] (nonstandard) \\ d. [so.se] (nonstandard but the most frequent variant)
}

In addition to the high frequency of the output consonant [s] in onset position due to neutralization, /s/ is also high in frequency as an input onset consonant. According to a dictionary study (Shin 2010), /s/ is a frequent input onset consonant (11.7\%) among 18 consonants in Korean. This in turn means that [sV(C)] is a frequent 
syllable structure in Korean, as can be seen in the second syllable of the nonstandard suffixed form [tak. $\underline{\text { si] }}$ 'chicken-NOM'.

Results of the above studies imply that frequency matters when it comes to selecting an epenthetic consonant among others. Speakers might be influenced by the frequency effects of neutralized stem-final consonants and onset consonants. Therefore, selecting [s] as an epenthetic consonant in onset position is a reasonable strategy in the production of nonstandard suffixed forms of nouns.

To conclude, I have shown that stem-final consonant clusters exhibit variation particularly when they are followed by a vowel-initial suffix in nonstandard Korean. Nonstandard suffixed forms of nouns vary: they may undergo mere consonant deletion or consonant epenthesis in addition to consonant deletion. Consonant epenthesis is motivated by the interaction between the Base identity effect at the segmental and suprasegmental levels and the frequency effects on the segmental choice. This study contributes to capturing and documenting a wider range of varieties in spoken Korean and provides phonological reasons for the novel form, which has not yet been well-studied in the phonology literature.

\section{References}

Aguero-Bautista, Calixto (1998). Cyclic and identity effects in Spanish diminutives and augmentatives. Unpublished Phonology Generals paper, MIT.

Albright, Adam (2002a). The identification of bases in morphological paradigms. Ph.D. dissertation, UCLA.

Albright, Adam (2002b). Islands of reliability for regular morphology: Evidence from Italian. Language 78.4: 684-709.

Albright, Adam (2005). The morphological basis of paradigm leveling. Downing, Laura, Tracy Alan Hall \& Renate Raffelsiefen (eds.), Paradigms in Phonological Theory, Oxford University Press, 17-43.

Albright, Adam (2008). Explaining universal tendencies and language particulars in analogical change. Jeff Good (ed.), Linguistic Universals and Language Change, Oxford University Press, 144-181.

Côté, Marie-Hélène (2000). Consonant cluster phonotactics: A perceptual approach. Ph.D. dissertation, MIT.

Jun, Jongho. (2010) Stem-final obstruent variation in Korean. Journal of East Asian Linguistics 19.2: 137-179.

Jun, Jongho \& Jeehyun Lee (2007). Multiple stem-final variants in Korean native nouns and loanwords. Journal of the Linguistic Society of Korea 47: 159-187.

Kenstowicz, Michael (1996). Base-Identity and Uniform Exponence: Alternatives to cyclicity. Durand, Jaques \& Bernard Laks (eds.), Current Trends in Phonology: Models and Methods, European Research Institute of the University of Salford, 363-393.

Kenstowicz, Michael (2005). Paradigm uniformity and contrast. Downing, Laura J., Tracy Alan Hall \& Renate Raffelsiefen (eds.), Paradigms in Phonological Theory, Oxford University Press, 145-169.

Ko, Heejeong (2006). Base-output correspondence in Korean nominal inflection. Journal of East Asian Linguistics 15.3: 195-243.

Lee, Yongsung (1993). Topics in the vowel phonology of Korean. Ph.D. dissertation, Indiana University.

Lee, Yongsung (2001). The noun-verb asymmetry in Korean phonology. Studies in Phonetics, Phonology, and Morphology 7: 375-397.

Shin, Jiyoung (2010). Phoneme and syllable frequencies based on the analysis of entries in the Korean dictionary. Korean Journal of Communication Disorders 15, 94-106.

Steriade, Donca (2000). Lexical conservatism and the notion base of affixation. Ms. UCLA.

The National Institute of the Korean language (2010). Sejong Corpus of Korean (3rd edition).

The National Institute of the Korean language (2011). Sejong Corpus of Korean (4th edition).

Vennemann, Theo (1988). Preference laws for syllable structure and the explanation of sound change: with special reference to German, Germanic, Italian, and Latin. Berlin, Mouton de Gruyter.

Yun, Jiwon (2008). Noun-verb asymmetries in Korean phonology. Abner, Natasha \& Jason Bishop (eds.) Proceedings of the 27th West Coast Conference on Formal Linguistics, 449-457. 